\title{
Gesetzmäßigkeiten des Wachstums und der Entwicklung von Chaetomorpha darwinii (Chlorophyta, Cladophorales)
}

\author{
P. KORNMANN \\ Biologische Anstalt Helgoland, Meeresstation, Helgoland
}

\begin{abstract}
Regularities of growth and development in Cbaetomorpha darwinii (Chlorophyta, Cladophorales). The monosiphonous filaments of the Australian species Chaetomorpha darwinii are most conspicuous in regard to the dimensions of their cells, which resemble strings of large and glistening pearls. Some 20 germlings could be isolated from samples of Callipsygma reilsonii and Rhipiliopsis peltata which were kindly sent to me by Mrs. S. C. Ducker, Melbourne. In culture they developed into mature gametophytes or sporophytes of 10-60 cm length. Developmental studies revealed a life cycle of isomorphic generations. $\mathrm{C} h$. darwinii is a most suitable object for investigations on growth and cell-physiology. Cells increase in length and width simultaneously. The growth process is confined to an aequatorial zone; since cross-walls and adjacent parts of the side walls lack the capacity for growth, the cells become increasingly barrel-shaped. The growth rate is distinctly influenced by the daily rhythm of illumination. The cell wall of Chaetomorpha species hitherto investigated in this regard is finely lamellated, with microfibrils crossing at a distinct angle (Frei \& Preston 1961a). This structure is the prerequisit for the simultaneous elongation and enlargement of the cell, and thus provides the basis for spiral-growth observed in several Chaetomorpha-species (FREI \& Preston 1961b, Kornmann 1968). Filament growth is exponential and results from the steady growth of all its cells which divide periodically. The cell-division exemplifies centripetally sectioning, with the margin of the iris-like cross-wall advancing steadily at an average speed of $17 \mu / \mathrm{h}$. Normally growing Chaetomorpha cells show no morphological polarity; their protoplast is concentrated in an aequatorial girdle. When plasmolized, the protoplast remains attached to the upper cross-wall (FREI \& PRESTON 1961a). A similar polarity-phenomenon was observed in quite a normally occuring process: the protoplasmatic layer containing nascent swarmers withdraws from the side walls and the lower cross-wall. A dark-coloured, folded sack remains attached to the upper cross-wall, until the zoids become motile spontaneously. Further manifestations of polarity are: the expansion of the basal cell in alga fragments and the subdivision of the filamentous thallus into segments of four cells whose height differs in a regular sequence.
\end{abstract}

\section{EINLEITUNG}

Der Freundlichkeit von Frau Sophie C. Ducker verdanke ich das Untersuchungsobjekt dieser Arbeit, die stattlichste aller Chaetomorpha-Arten. Anfang Dezember 1966 sandte sie mir Proben von Callipsygma wilsonii und Rhipiliopsis peltata von Point Lonsdale, Victoria, Australien. Es sollte versucht werden, diese beiden Grünalgen zu kultivieren. Ihre Thalli beherbergten jedoch so viele Epiphytenkeimlinge, Cyanophyceen und Diatomeen, daß die Wirtsalgen nach kurzer Zejt völlig überwuchert waren. 
Etwa 30 verschiedene Arten von Grün-, Braun- und Rotalgen konnten isoliert und in Kultur genommen werden. Unter den zahlreichen Ectocarpaceen waren Arten, die Giffordia sandriana, Feldmannia globifera und Acinetospora crinita zumindest sehr ähnlich sind; erwähnt seien noch eine Leptonematella-Art und die fädigen Thalli von Splachnidium (PrICE \& Ducker 1966). Eine der drei isolierten Chaetomorpha-Arten war durch ihre dickfädigen Keimlinge besonders bemerkenswert; aus ihnen entwickelten sich großzellige Fäden von über $60 \mathrm{~cm}$ Länge, die Frau Ducker als Chatomorpha darwinii erkannte. Die leicht kultivierbare Alge ist ein ideales Objekt für das Studium von Wachstumsvorgängen und zellphysiologischen Untersuchungen.

\section{LANGENWACHSTUM DES FADENS}

In den Abbildungen 1 und 2 ist das Wachstum einer aus dem Ursprungsmaterial isolierten Pflanze während 55 Tagen aufgezeichnet. Da die Wirtsalge bereits Ende November gesammelt wurde, muß das vierzellige Fädchen am Beginn der Serie mindestens 7 Wochen alt gewesen sein. Seine Basis war durch Cyanophyceen verdeckt; Erythrotricbia und Giffordia, die sich auf dem Faden ansiedelten, mußten wiederholt entfernt werden. Bis zum 28. Januar wurde das Fädchen mit Hilfe eines Okularmikrometers gezeichnet, danach photographiert. Die Kultur erfolgte in Erdschreiberlösung bei $15^{\circ} \mathrm{C}$ und täglich 14 stündigem Licht einer Tageslicht-Leuchtstofflampe 40 Watt in etwa $30 \mathrm{~cm}$ Entfernung. Der Faden, der nach zweimonatiger Kultur beinahe $11 \mathrm{~cm}$ Länge erreichte, geht im wesentlichen aus der Apikalzelle des am 18. Januar vierzelligen Keimlings hervor, während aus der Subapikalzelle in dieser Zeit nur vier Zellen entstanden. Die römischen Ziffern I bis VII kennzeichnen die Querwände zwischen den ersten acht Zellen des Fadens in der Reihenfolge ihrer Entstehung. Wie Abbildung 1 zeigt, teilen und strecken sich die Zellen zunächst ziemlich gleichmäßig; am 21. Februar sind alle Fadenabschnitte vierzellig mit Ausnahme der beiden obersten, deren Sonderstellung sich abzuzeichnen beginnt. Die weitere Entwicklung ist in Abbildung 2 schematisch dargestellt. Die längs eines Fadens eingetragenen arabischen Ziffern geben die Anzahl der Zellen in dem jeweiligen Fadenabschnitt an. Die oberste Zone mit der Apikalzelle wächst am stärksten und weist am Ende des Versuchs 34 Zellen auf. Die darunterliegende Zone enthält nur etwa halb so viele Zellen, in vier Teilungsschritten aus ihrer Ursprungszelle entstanden. In den basalen Zonen ist die 'Teilungsaktivität noch geringer; in diesen Abschnitten entstanden acht oder weniger Zellen. Drei Wochen nach dem Abbruch der Registrierung begann der Faden in seinem mittleren Teil fertil zu werden, während die Zellen des Spitzenabschnitts zunächst noch weiterwuchsen.

Der Wachstumsverlauf zeigt das Bild einer Exponentialfunktion. Alle Zellen strecken sich mit nahezu gleicher Geschwindigkeit, so daß ihre jeweilige Anzahl den Zuwachs bestimmt. Diese Zusammenhänge werden im nächsten Abschnitt noch ausführlicher dargestellt. Leichte Unstetigkeiten der Kurve - die Längenzunahme des Fadens bleibt am 4., 15. und 23. Februar hinter den erwarteten Werten zuriick - sind wahrscheinlich durch Ungleichmäßigkeiten der Kulturbedingungen verursacht, zu denen insbesondere der Epiphytenbewuchs beigetragen haben mag. Bei sorgfältiger 
Pflege reiner Kulturen - vor allem ausreichend häufiger Erneuerung des Nährmediums lassen sich solche Schwankungen des Längenwachstums vermeiden. Der unregelmäßige Rhythmus der Zellteilungen dürfte jedoch auf inneren Ursachen beruhen; die Apikalzelle teilt sich in Abständen zwischen 4 und 8 Tagen, die Fadenzellen schreiten nach 5 bis 10 Tagen zur Teilung.

\section{WACHSTUM UND DIFFERENZIERUNG DER EINZELNEN ZELLEN}

Die wachsende Chaetomorpha-Zelle streckt und verbreitert sich gleichzeitig. Da die Querwände nicht wachstumsfähig sind, werden die Zellen zwangsläufig tonnen-

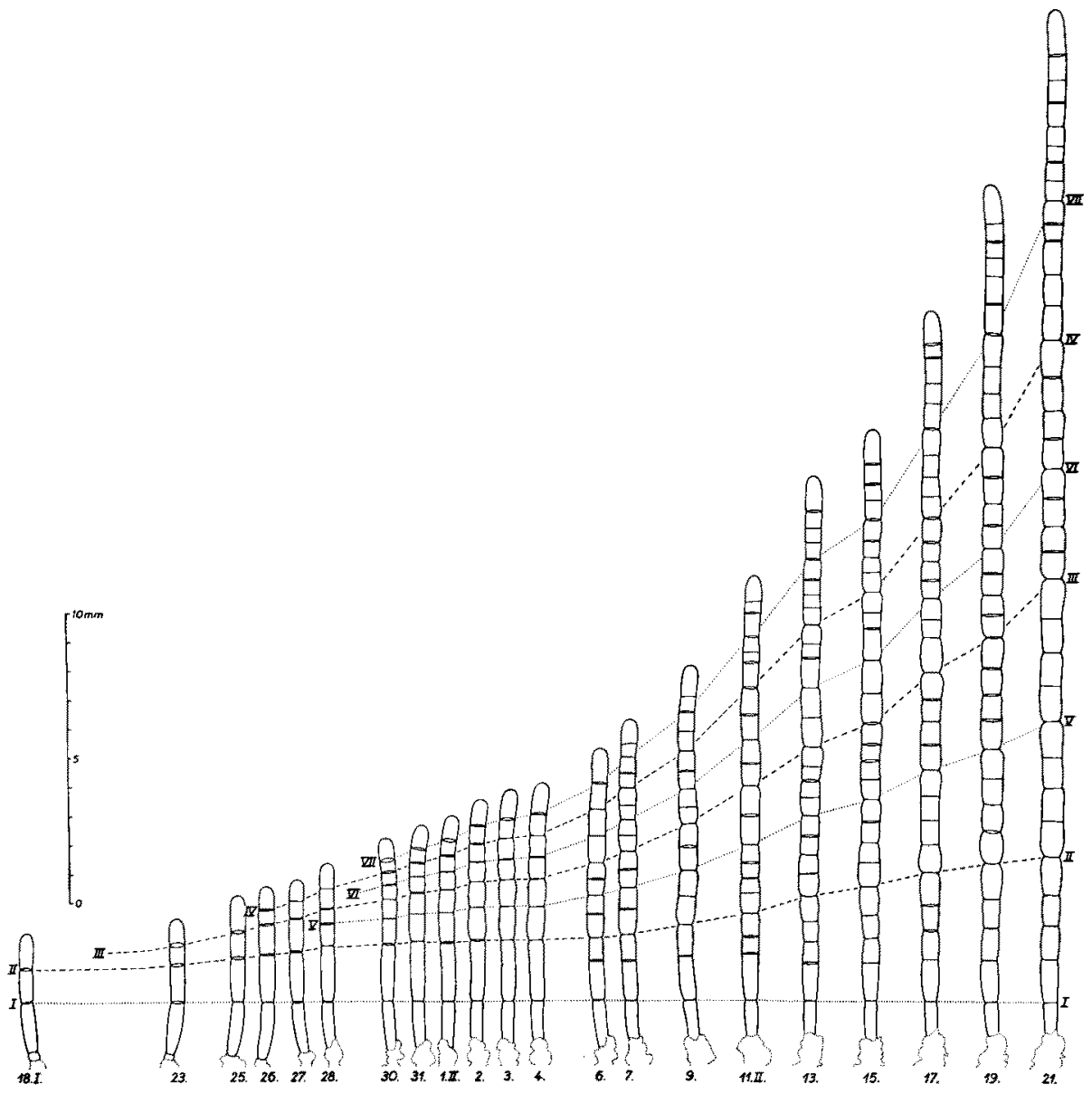

Abb. 1: Chaetomorpha darwinii. Wachstum eines am Beginn der Serie etwa 7 Wochen alten Fädchens. Die Ziffern I-VII kennzeichnen die Querwände in der Reihenfolge ihrer Entstehung 


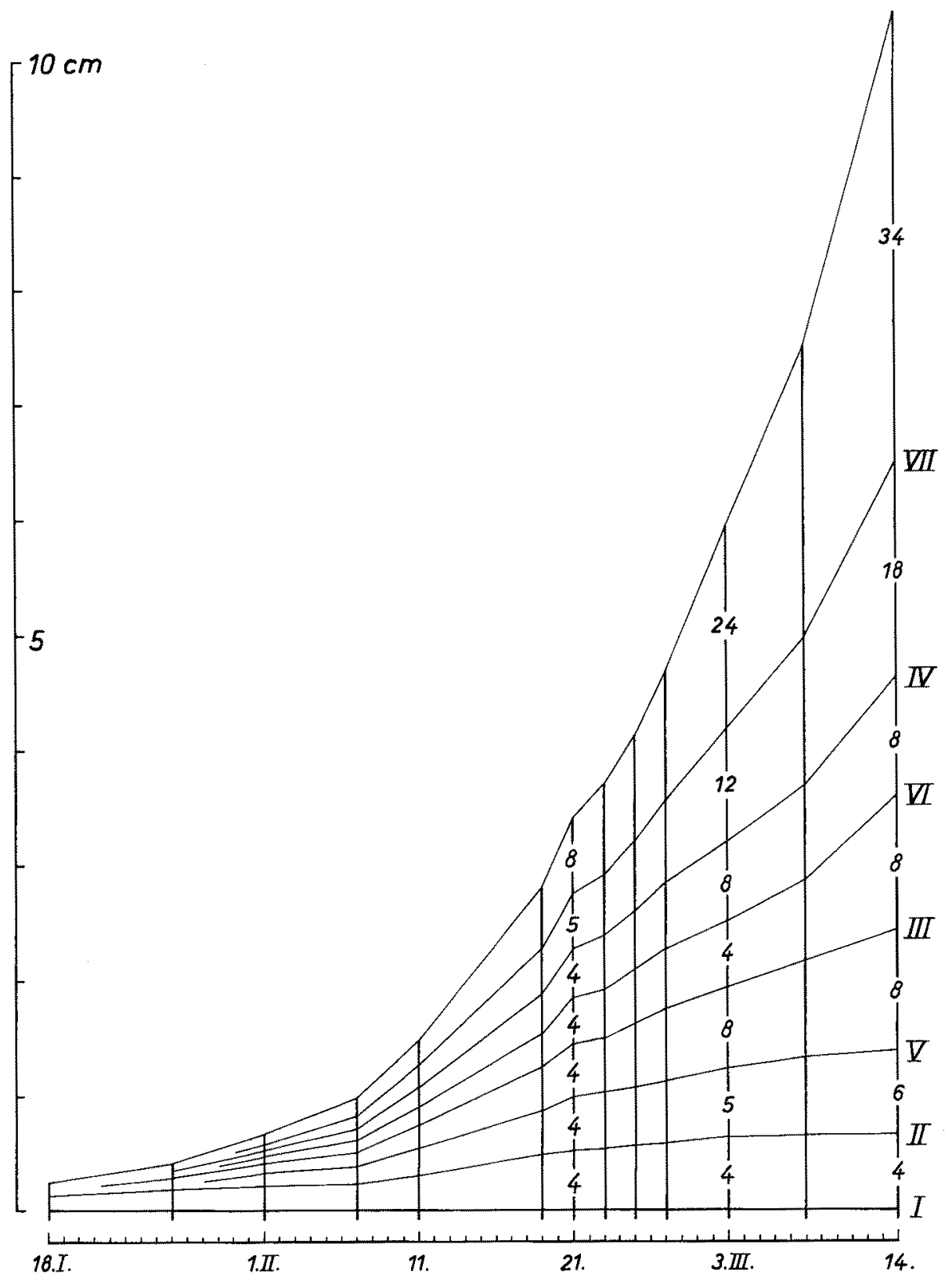

Abb. 2: Chaetomorpha darwinii. Wachstumsverteilung des in Abbildung 1 dargestellten Fadens während der zweimonatigen Beobachtungszeit. Die arabischen Ziffern geben die Anzahl der Zellen in den einzelnen Fadenabschnitten an 
förmig (Abb. $3 A-C$ ). Nach ihrer letzten Teilung können sie stark anschwellen und nahezu kugelig werden. Ein ausgewachsener Faden sieht dann wie eine Kette aus glänzenden Perlen aus, bevor er fertil wird $(D)$.

Näheren Aufschluß über den Wachstumsort geben Beobachtungen an „markierten“ Zellen. Gelegentlich lassen sich fädige Epiphyten an einer Reihe aufeinanderfolgender Bilder wiederfinden. Ihr Auseinanderrücken zeigt den Wachstumsort

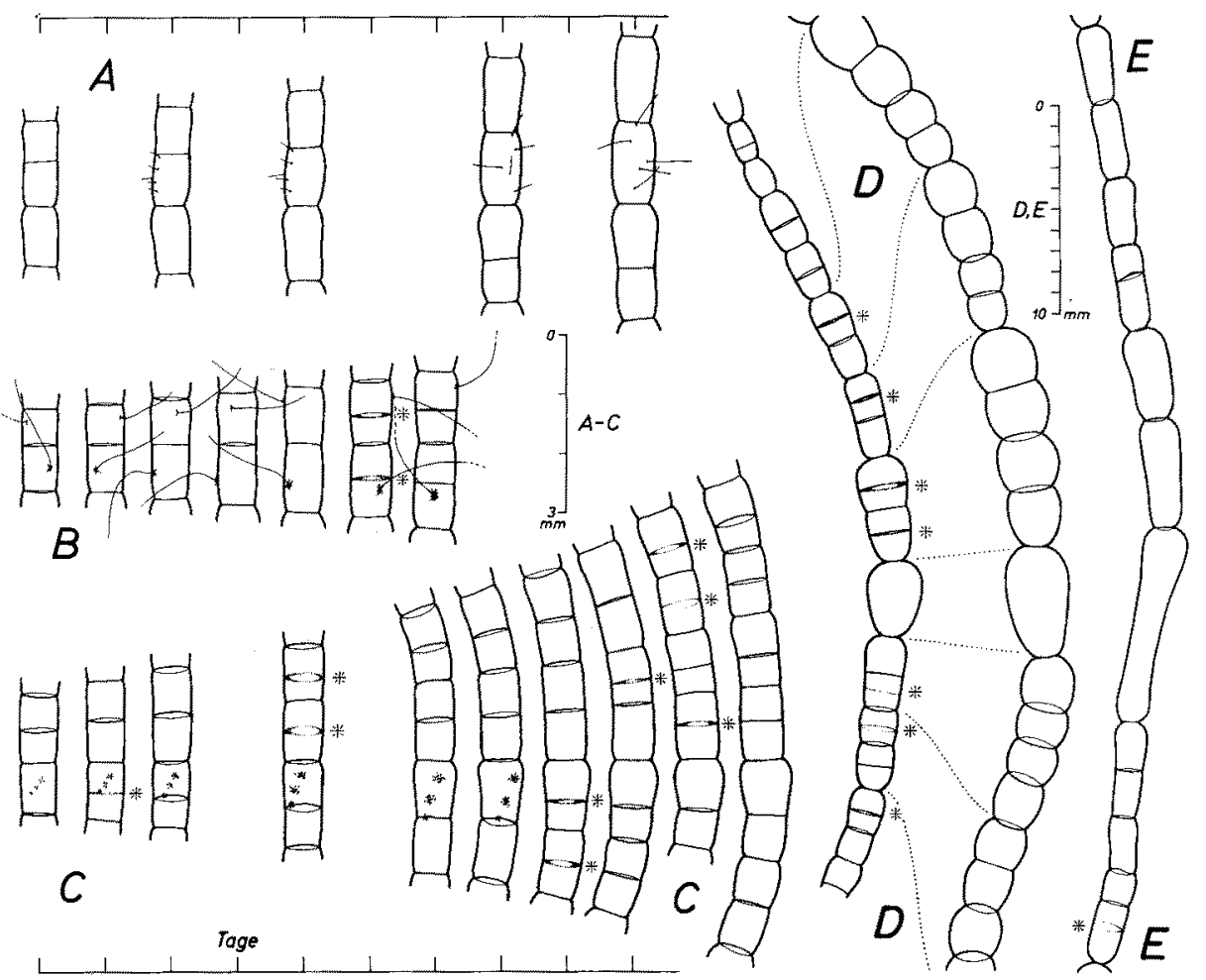

Abb. 3: Chaetomorpha darreinit. Wachstum und Differenzierung der Zellen. A-C Epiphyten kennzeichnen den Wachstumsort. $D$ Nach ihrer letzten Teilung vor dem Fertilwerden schwellen die Zellen kugelig an. Bilder im Abstand von drei Wochen. E Fadenstück mit langgestreckten Zellen. Mit einem + bezeichnete Zellen befinden sich in Teilung

der Zelle an. Aus den Abbildungen $3 A$ bis $C$ geht klar hervor, daß die Wachstumszone beiderseits des Zelläquators liegt. Epiphyten im oberen beziehungsweise unteren Viertel einer Zelle verändern ihre Lage nicht.

Infolge der Lokalisierung des Wachstums auf eine äquatoriale Zone gelangen wahllos auf den Zellen sich ansiedelnde Epiphyten nach wenigen Teilungsschritten in die nicht streckungsfähige Nähe der Quermembranen. So entstehen die Epiphytenringe, die häufig in erstaunlich regelmäßigen Abständen auf Chaetomorpha-Fäden zu finden sind (vgl. KornmanN 1968, Abb. 9). Je älter ein solcher "Knoten“ ist, um so dichter und länger sind die ihn besiedelnden Epiphyten. Bei Chaetomorpha darwinit sind diese 
Stellen durch eine besonders tiefe Einschnürung zwischen den benachbarten Zellen ausgezeichnet; sie entsprechen den in den Abbildungen 1 und 2 mit römischen Ziffern bezeichneten ältesten Querwänden. Die Breite einer Querwand kennzeichnet ihr Alter im Fadenverband; diese morphologische Besonderheit kommt in Abbildung $3 \mathrm{D}$ anschaulich zum Ausdruck.

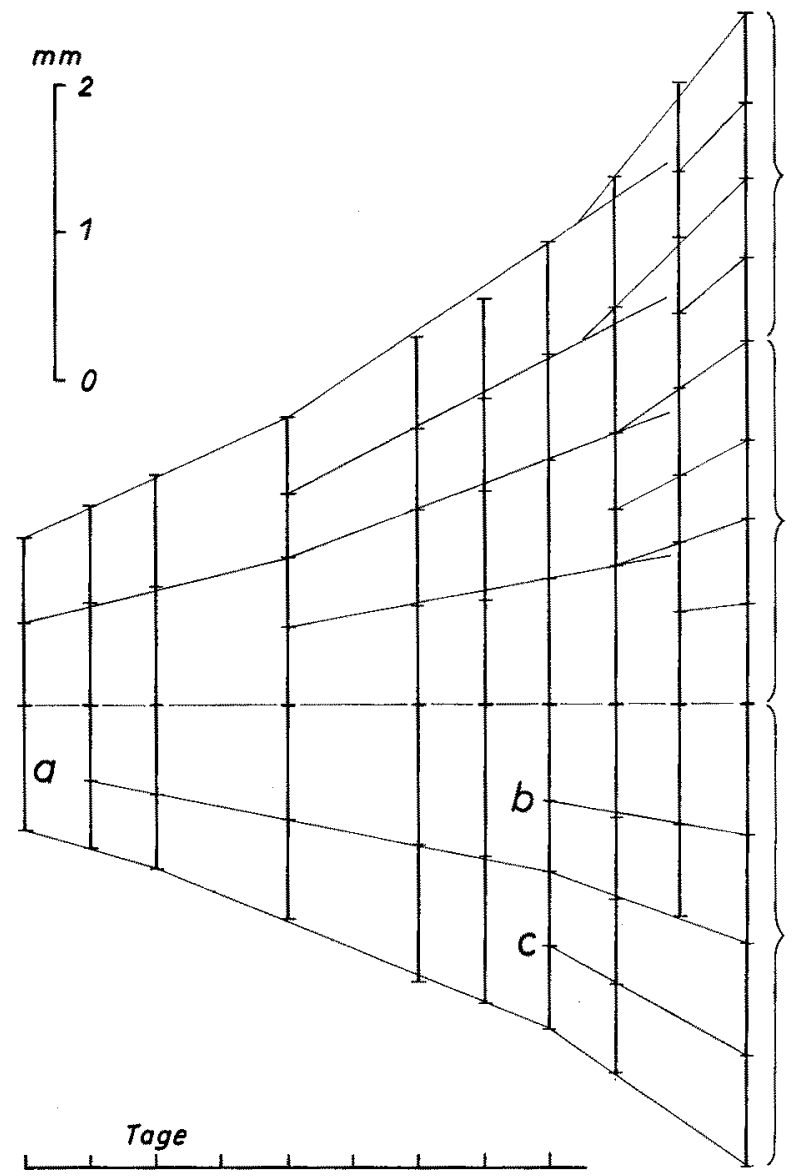

Abb. 4: Chaetomorpha darwinii. Wachstum, Teilungsmodus und Gliederung eines dreizelligen Fadenstückes während 11 Tagen. Weitere Erläuterungen im Text. Die Meßwerte des Diagramms sind Abbildung $3 \mathrm{C}$ entnommen

Die geringe Anzahl sehr großer Zellen macht Chaetomorpha darwinii zu einem Modell für das Studium der Gesetzmäßigkeit eines interkalar wachsenden monosiphonen Fadens. In Abbildung 4 ist das Wachstum des in Abbildung $3 \mathrm{C}$ dargestellten Fadenstückes näher analysiert, es wurde im allgemeinen täglich etwa zur gleichen Uhrzeit photographiert. In dem Diagramm sind nur die Längen der einzelnen Zellen aufgezeichnet und geradlinig miteinander verbunden. Der tägliche Zuwachs ist bei 
allen Zellen gleich, unabhängig von ihrer Länge beziehungsweise ihrem Alter; er beträgt in dem abgebildeten Beispiel etwa $80 \mu$. Daher ändert sich der Neigungswinkel als Ausdruck der Wachstumsgeschwindigkeit mit jeder Zellteilung sprunghaft um jeweils den gleichen Wert. Der exponentielle Charakter der Wachstumskurve (Abb. 2) erklärt sich also als Summe der gleichmäßigen Streckung aller Zellen eines Fadens,

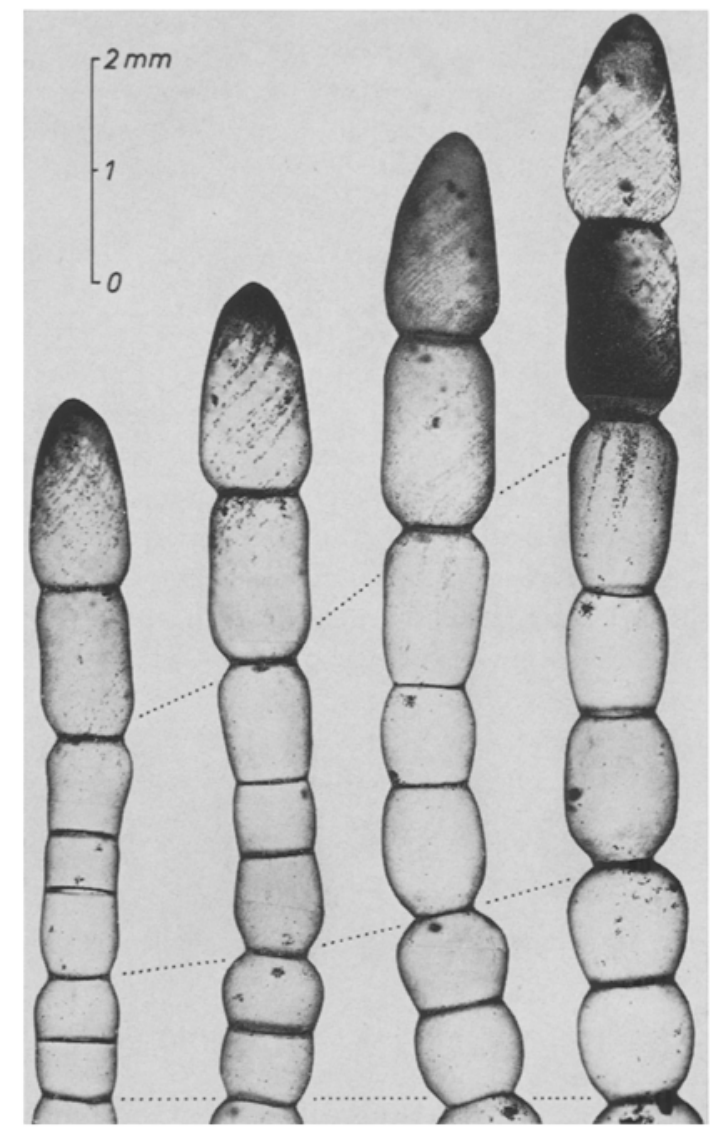

Abb. 5: Chaetomorpha darwinii. Die streifige Anordnung epiphytischer Cyanophyceen veranschaulicht die Drehung der wachsenden Zellen. Aufnahmen im Abstand von zwei Tagen; im letzten Bild ist die Apikalzelle ausgeschwärmt, in der subapikalen Zelle sind die Schwärmer phototaktisch angesammelt

deren Anzahl in den einzelnen Fadenabschnitten in exponentiellem Verhältnis - wenn auch nicht im gleichen Rhythmus - zunimmt.

Wachstum und Differenzierung der Chaetomorpha-Zelle lassen sich leicht mit den Feststellungen über den Feinbau ihrer Membran (FreI \& Preston 1961a) und die von FREI \& PRESTON (1961b) zuerst beobachtete Drehung eines wachsenden Fadens um seine Längsachse in Einklang bringen. Die Chaetomorpha-Membran besteht aus La- 
mellen von kreuzweise in einem bestimmten Winkel geschichteten Mikrofibrillen. Dieser Feinbau wird nicht nur verständlich, sondern ist geradezu eine Voraussetzung, wenn man die Membran nicht statisch als ein fertiges Gebilde, sondern dynamisch in ihrer Entstehung betrachtet, deren lokalisiertes Wachstum in der Längs- und Querrichtung erfolgt und zu einer tonnenförmigen Zelle führt. Die Verlängerung der beiden Mikrofibrillensysteme bewirkt die Drehung des Membranmantels. Beobachtungen an einer sehr raschwüchsigen Chatomorpha-Art von List/Sylt ließen mich bereits eine Beziehung zwischen der axialen Drehung und der Dickenzunahme des Fadens vermuten (Kornmann 1968). Die an diesem Objekt beobachteten tagesperiodischen Schwankungen erklären sich wahrscheinlich durch eine rhythmisch wechselnde Intensität des Wachstums der beiden Mikrofibrillensysteme. Die unterschiedliche Textur der von FREI \& PRESTON untersuchten Zellwände von Valonia und Chaetomorpha oder Cladophora dürfte die jeweilige Zellform und ihre Entstehungsgeschichte widerspiegeln. Es wäre sehr aufschlußreich, den Feinbau der Membran zylindrischer und kugelig aufgeblähter Zellen von Cbaetomorpha darwinii zu vergleichen.

Die Drehung des Fadens um seine Achse ließ sich auch bei Chaetomorpha darwinii nachweisen. Als Zeiger dienten Epiphyten an der Spitze eines Fadenstückes, dessen Basis an der Drehung verhindert war. Besonders eindrucksvoll aber wird die Membrandrehung an dem streifigen Cyanophyceen-Belag in Abbildung 5 demonstriert. Die Apikalzelle eines Fadens trug eine Kappe von Cyanophyceen, die an ihrem unteren Rand in die Wachstumszone gerieten und sich in spiraligen Streifen anordneten. In dem Bild rechts hat die inzwischen fertil gewordene Apikalzelle ihre Schwärmer entleert, in der darunterliegenden Zelle sind sie einseitig phototaktisch angesammelt.

Es kann heute nicht mehr verwundern, daß die Membran von Acrosiphonia (Spongomorpha arcta bei Nicolai \& Preston 1959) eine andere Feinstruktur als Cladophora aufweist. Ihre Entwicklungsgeschichte sowie ihr Wachstum und Aufbau schließen Acrosiphonia eindeutig aus der Ordnung der Cladophorales aus.

\section{TAGESRHYTHMUS DES LANGENWACHSTUMS}

In dem Diagramm Abbildung 4 wurden die jeweiligen Längenmaße der Zellen eines Fadenabschnittes in Abständen von einem oder zwei Tagen aufgezeichnet und geradlinig miteinander verbunden. Die Darstellung sagt also nichts über den Wachstumsverlauf innerhalb einer Tagesperiode aus, in der Licht und Dunkelheit in einem Rhythmus von $14: 10$ Stunden wechseln. Daß die Wachstumsgeschwindigkeit der Zellen durch den Lichtrhythmus deutlich beeinflußt wird, wurde bei der Auswertung einer Beobachtungsreihe mit täglich zweimaliger Registrierung eines Fadenendes erkannt, einer Serie zum Nachweis der Drehung des Fadens um seine Längsachse. Obwohl die Photos nicht einmal zu Beginn und am Ende der 14stündigen Lichtperiode aufgenommen wurden, ist das raschere Längenwachstum bei Licht unverkennbar (Abb. 6). Der hier nur kurz geschilderte Befund läßt eine eingehendere Analyse des Wachstumsverlaufs in Abhängigkeit von den experimentell möglichen Variationen des Lichtgenusses lohnend erscheinen.

Es sei darauf hingewiesen, daß das Wachstum der Chaetomorpha-Zelle keine 
große Periode des Wachstums zeigt, „dieses Ansteigen der Wachstumsgeschwindigkeit bis zu einem Höhepunkt und dann wieder ein Nachlassen, wenn die Zelle ihre endgültige Größe erreicht hat" (Schumacher 1967, p. 333). Sollten sich die Zellen der Streckungszonen von Sproß und Wurzel anders verhalten? Man wird es nach der Feststellung des gleichförmigen Wachstums der bisher untersuchten Zellen bezweifeln dürfen; die Streckung der Apikalzellen von Acrosiphonia und Spongomorpha zeigt ebenso wie das interkalare Wachstum der Zellen von Chaetomorpha darwinii oder der Internodialzelle von Nitella (GreEN 1954) keine endogene Rhythmik. Zudem setzt die große Periode der Streckung eines Organs keine rhythmische Streckung seiner Einzelzellen voraus.

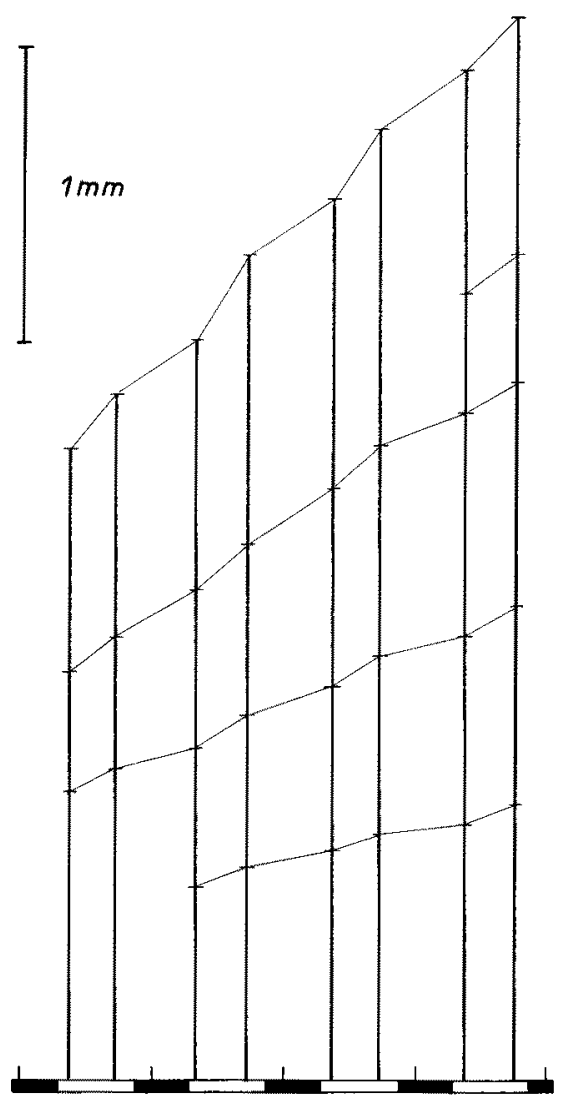

Abb. 6: Chaetomorpha darwinii. Tagesrhythmus des Längenwachstums im Licht-Dunkel-Wechsel von $14: 10$ Stunden

\section{DIE ZELLTEILUNG}

Die großen Zellen von Chaetomorpha darwinii sind ein Musterbeispiel für zentripetale Querwandbildung. Wie eine Irisblende sich schließt, so verengt sich der Ring 
der neuen Querwand und schnürt die Zelle durch (Abb. 7). Die für diesen Vorgang benötigte Zeit hängt von der Breite der Zelle ab. Die hier abgebildeten Zellen von etwa $0,5 \mathrm{~mm}$ Durchmesser werden in etwa 14 Stunden geteilt, während die Teilung bei einer 1,6 mm breiten Zelle mehr als zwei Tage dauert. Im allgemeinen wird die Quermembran als konzentrischer Ring auf der Längswand angelegt. Die Teilung kann aber auch - besonders bei dickeren Fäden - lokal beginnen und nach beiden Seiten auf dem Zelläquator fortschreiten. Dabei entstehen zuerst sichelförmige, später exzentrisch sich schließende Teilungsmembranen.

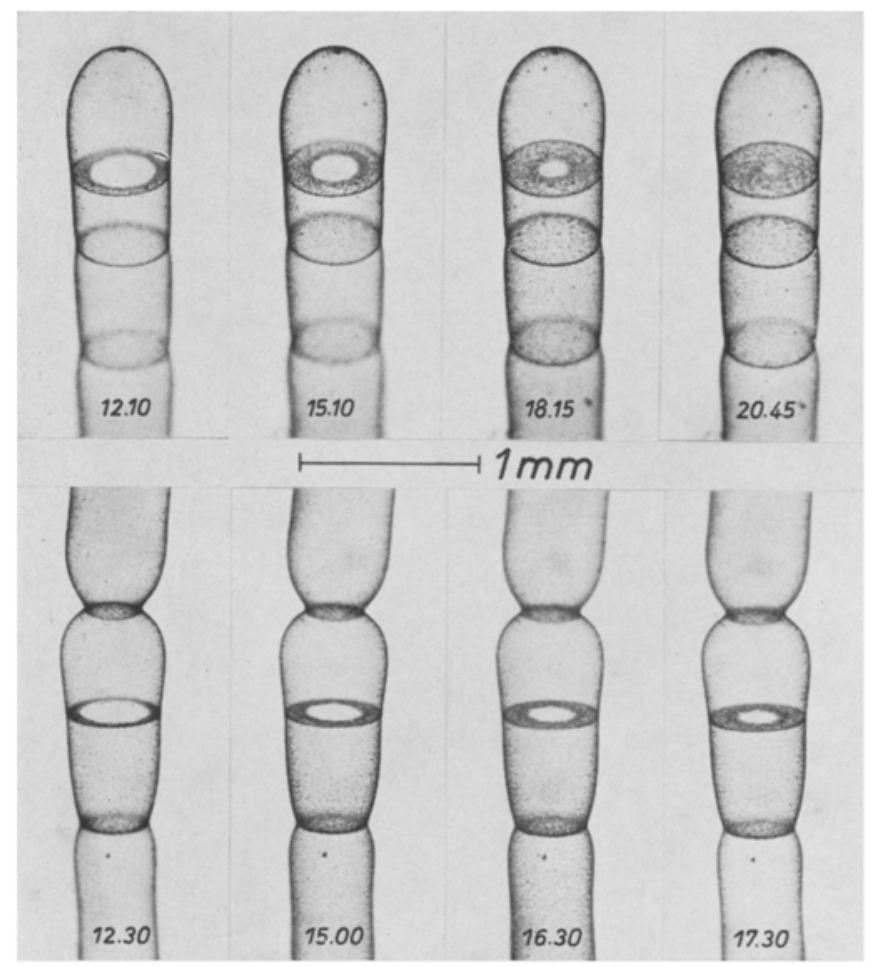

Abb. 7: Chaetomorpha darwinii. Zentripetale Teilung einer Apikal- und einer Fadenzelle

Als erstes Anzeichen der Teilung erscheint in der gürtelförmigen Zone der stärksten Anreicherung des Protoplasten eine ganz feine, äquatoriale Linie, auf der sich dann der Membranring aufsetzt. Diese Anfangsstadien sind in Abbildung $8 A-C$ an fixierten und mit Eisenkarminessigsäure gefärbten Präparaten dargestellt. Bei $D$ ist der entstehende Membranring an einer Falte des Protoplasmamantels im Profil sichtbar. In ihm liegen zu beiden Seiten einer Mittellamelle zahlreiche Kerne dicht aneinandergereiht ( $E$, andere Ebene), wie auch auf den anderen Bildern eine starke Anhäufung von Kernen auf beiden Seiten des gerade entstandenen Membranringes zu erkennen ist. Die Teilung der Zelle steht - wie bei anderen Vertretern der Cladophorales - nicht in unmittelbarer Beziehung zur 'Teilung der Kerne, 


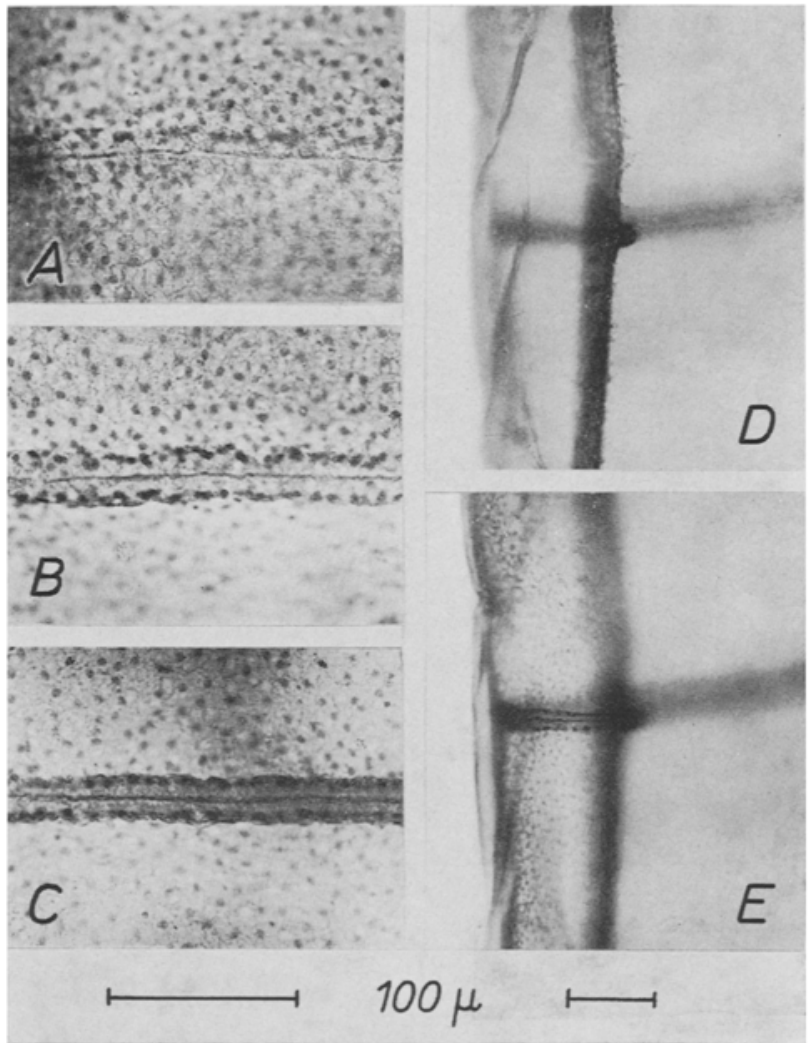

Abb. 8: Chaetomorpha darwinii. Anfangsstadien der Zellteilung. $A-C$ Aufsicht, $D, E$ an einer Falte des Wandbelags im Profil. Färbung mit Eisenkarminessigsäure

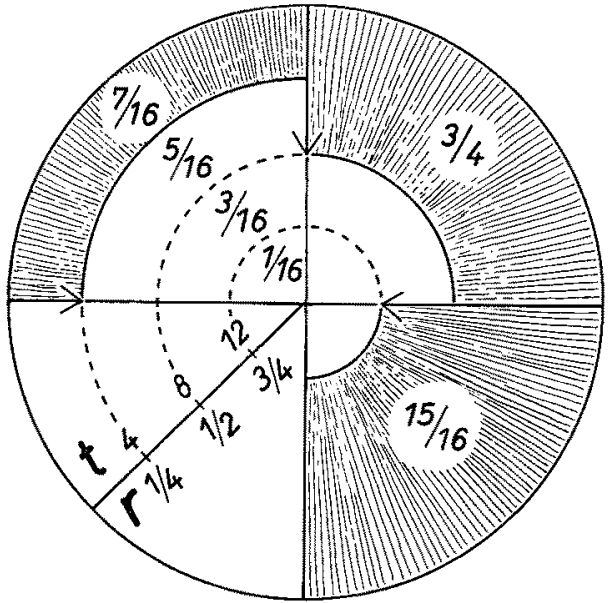

Abb. 9: Chaetomorpha darteinii. Schema des Wachstums der Teilungsmembran. Mit gleichmäßiger Geschwindigkeit radial fortschreitend, vermindert sich die in der Zeiteinheit gebildete Membranfläche immer mehr 
Die entstehende Querwand rückt längs des Radius mit einer gleichmäßigen Geschwindigkeit von durchschnittlich $17 \mu$ in der Stunde vor. Dies bestätigte sich bei der Auswertung einer größeren Anzahl von Meßreihen und photographischen Registrierungen. Wie die schematische Darstellung des Vorgangs in Abbildung 9 veranschaulicht, nimmt die in gleichen Intervallen gebildete Membranfläche immer mehr ab. So werden während der ersten Hälfte des Teilungsvorganges drei Viertel der neuen Querwand gebildet, im letzten zeitlichen Viertel entsteht nur noch ein Sechzehntel ihrer gesamten Fläche.

Die Aufsicht auf die sich schließende Quermembran läßt eine radiale Streifung erkennen, dagegen zeigt der Protoplast auf der fertigen Querwand eine weitmaschige netzige Struktur.

\section{POLARITATSERSCHEINUNGEN}

\section{Plasmolyse während der Schwärmerreifung}

Ober Polaritätserscheinungen an Chaetomorpha-Zellen wurde schon öfter berichtet. FREI \& PRESTON (1961a) stellten an Chaetomorpha melagonium fest, daß sich bei der Plasmolyse der Protoplast erst von der Seitenwand, dann von der basalen Querwand ablöst. Die zusammengezogenen Protoplasten haften an der oberen Wand. Ein ganz ähnliches Verhalten zeigt der Protoplast von Chaetomorpha darwinii auch während eines ganz natürlich eintretenden, also nicht experimentell induzierten „Plasmolysevorgangs" im Zusammenhang mit der Schwärmerreifung. Die beginnende Fertilisierung einer Zelle gibr sich in einer Anderung ihrer Farbe zu erkennen: das leuchtende Grün der vegetativen Zelle geht in ein mattes Gelblichgrün über oder wird mitunter auch leicht orangefarben. Gleichzeitig bildet sich eine geringe Anzahl von Fenstern in dem Plasmabelag, in deren Mitte eine scharf begrenzte Zone, die spätere Austrittsöffnung der Schwärmer, sichtbar wird (Abb. $10 \mathrm{~A}, \mathrm{~B}$ ). Aus dem in diesem Stadium feinkörnig-netzigen Wandbelag differenzieren sich in kurzer Zeit die Körper der Schwärmer (C). Sie liegen noch immer in einer protoplasmatischen Schicht eingebettet. Diese löst sich spontan zuerst von der Seitenwand, dann auch von der basalen Querwand der Zelle ab (Abb. $10 D, E$ und $F$ ). An der hyalinen Basis des sich kontrahierenden Sackes ist deutlich eine Plasmahaut zu erkennen, oftmals auch ein dünner Plasmafaden, der diese Kappe zunächst noch mit der basalen Wand verbindet. In dem an der oberen Wand hängenden, stark kontrahierten und zuweilen eingefalteten Sack sind die Schwärmer mit ihrem Hinterende nach außen orientiert, bevor sie ganz plötzlich beweglich werden und sehr lebhaft in der Zelle umberschwimmen. Liegt ein Porus im Bereich der sich positiv phototaktisch ansammelnden Schwärmer, so gelangen sie in stetigem Strom ins Freie.

Die geschilderte Kontraktion der Wandschicht mit den bereits differenzierten Schwärmern erinnert an den Turgeszenzwechsel der Stephanopyxis-Zelle während der Furchung (von Stosch \& Drebes 1964, Abb. 5). Wie solche Spontanplasmolysen zustande kommen, ist in beiden Fällen unbekannt. Bemerkenswert ist es, daß die Chaetomorpha-Zelle bei dieser "Plasmolyse" nicht erschlaff; sie bleibt voll turgeszent, die 
Zellwand allein behält also die Eigenschaft einer semipermeablen Membran bis zum Austritt der Schwärmer.

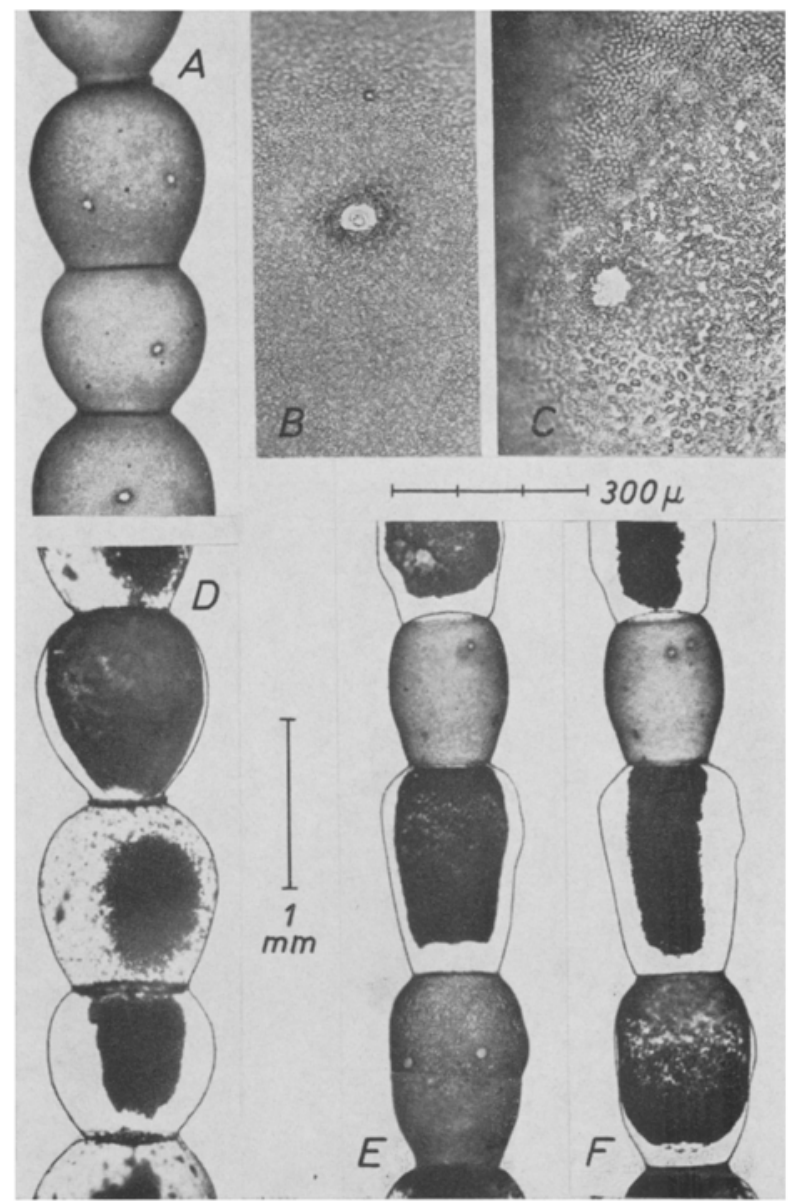

Abb. 10: Chaetomorpha darwinii. A-C Beginnende Fertilisierung. $A, D$ und $E, F$ Spontanplasmolyse während der Schwärmerreifung, im Abstand von einem Tag beziehungsweise zwei Stunden aufgenommen

\section{Basales Auswachsen eines Fadenstückes}

Eine weitere Polaritätserscheinung zeigt sich an zerschnittenen ChaetomorphaFäden: die unverletzte basale Zelle wächst rhizoid-oder sackartig aus. Uber solche Versuche haben KöHLER (1956) und KESSELER (1960) berichtet. Bei Chaetomorpha darwinii entsprechen das Ausmaß der Reaktion und ihr rascher Ablauf der Größe ihrer Zellen. Das Objekt wäre vielleicht geeignet, um die von KESSELER abgeleiteten 
zellphysiologischen Zusammenhänge dieses Vorgangs experimentell zu prüfen. Auch für das Studium des Ionenaustausches wären solche rasch sich aufblähenden Zellen vielleicht noch besser geeignet als im normalen Fadenverband wachsende Zellen. $\mathrm{Ab}$ bildung 11 zeigt an zwei Fragmenten eines Fadens den Reaktionsverlauf während sechs Tagen. Bereits nach einem Tag hat sich die basale Zelle stark vergrößert und füllt den Membranzylinder der zerschnittenen Zelle aus. Vor seiner Mündung bläht sie sich mehr

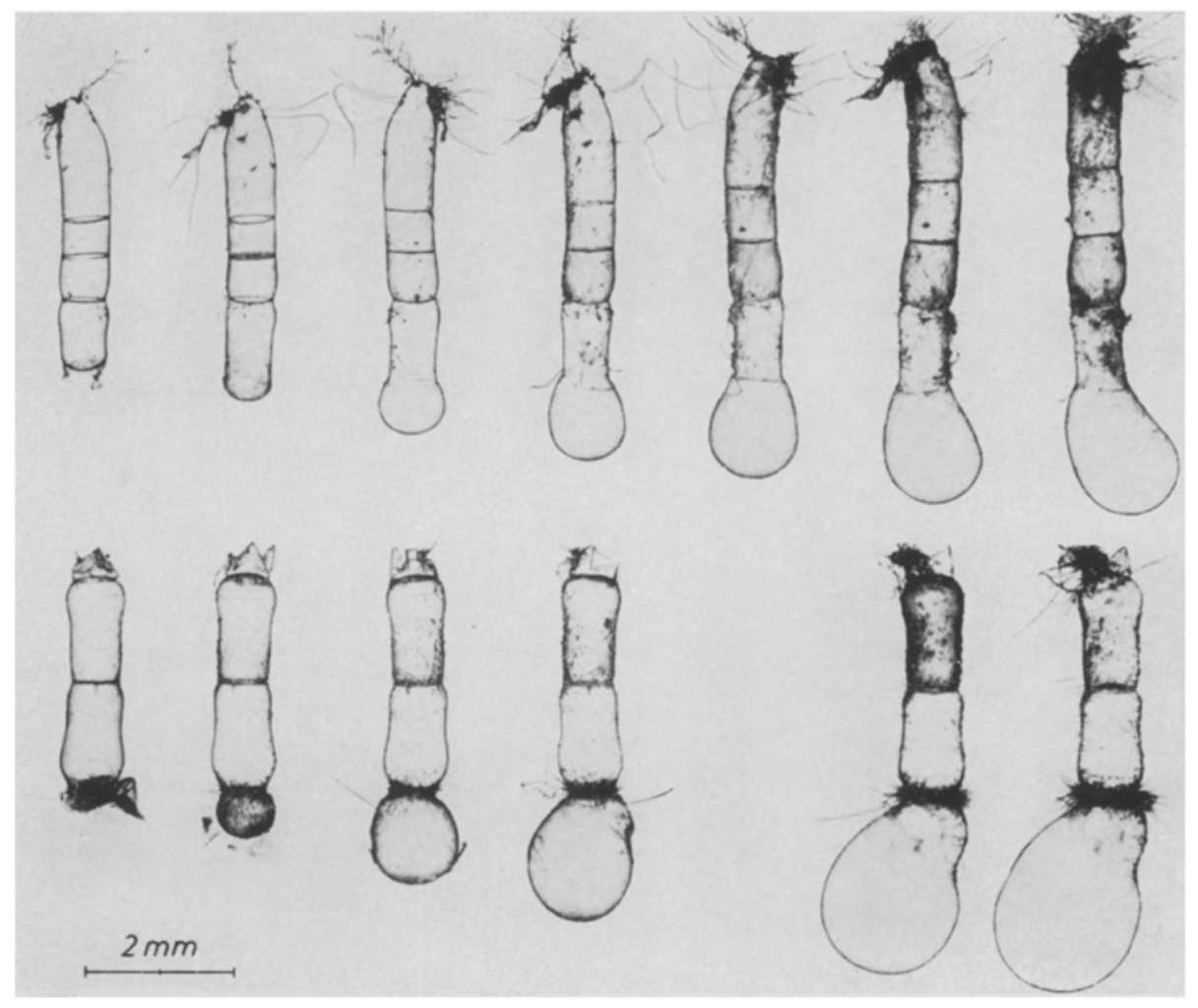

Abb. 11: Cbaetomorpha darwinit. Blasiges Auswachsen der basalen Zellen von Fadenstücken, in Tagesabständen aufgenommen. Die obere Zelle des Fadenstiickes unten rechts ist ausgeschwärmt

oder weniger kugelig auf und erreicht ein Mehrfaches ihres ursprünglichen Volumens. $\mathrm{Zu}$ dieser Reaktion ist immer nur die bas a le Zelle eines aus dem Zusammenhang des intakten Fadens gelösten Fragments fähig. Auch ohne experimentellen Eingriff läßt sich diese Erscheinung bei Chaetomorpha darwinii und bei vielen anderen fädigen Algen beobachten. Wenn eine Zelle im Fadenverband fertil geworden und ausgeschwärmt ist, so füllt der Protoplast der darüberliegenden vegetativen Zelle die leere Hülle aus.

Die Zellen eines in kurze Stücke zerschnittenen Fadens von Chaetomorpha darwinii werden im allgemeinen schon nach wenigen Tagen fertil. Die obere Zelle des 
zweigliedrigen Fadenstückes in Abbildung 11 ist am letzten Tage der Versuchsreihe bereits ausgeschwärmt. Die Zellen des Spitzenabschnitts (obere Bildreihe) sind zwar noch geringfügig gewachsen, sie stehen aber am Ende der Beobachtung kurz vor der Schwärmerbildung. Die aufgeblähten Basalzellen mit ihrem weitmaschigen Protoplasmanetz gehen nach kurzer Zeit zugrunde. Es wäre sicher sehr aufschlußreich, die Feinstruktur ihrer Wandung mit dem submikroskopischen Bild der Längs- und Quermembranen normaler Fadenzellen zu vergleichen.

Das polare Auswachsen der Basalzelle eines Fadenstückes ist ein echter Wachstumsvorgang, der durch eine Verlagerung des Protoplasten an die Basis der Zelle eingeleitet wird. Die Membran der Chaetomorpha-Zelle wächst immer nur an den Stellen, wo der Protoplast verdichter ist. Nur in diesen Bereichen wird die Zellwand plastisch und durch den Turgordruck dehnbar und wachstumsfähig. Dies gilt nicht nur für das basale Auswachsen der Endzelle eines zerschnittenen Fadens, sondern auch für das normale Wachstum der Zellen im Fadenverband. Schon die subjektive Beobachtung lebender Fäden läßt eine Verdichtung des Protoplasten in einer Gürtelzone erkennen. Gefärbte Zellen zeigen eine Anreicherung von Kernen in dieser Zone (KormmanN 1968).

\section{Gliederung des Fadens}

Nach der Teilung reichert sich der Protoplast in beiden Zellen wieder in einer ringförmigen Zone an. Diese Gürtel liegen aber häufig nicht in gleichem Abstand von der gemeinsamen Querwand; in der basalen Schwesterzelle rückt er bis etwa zur Zellmitte vor, während er in der apikalen unterhalb der Zellmitte verbleibt. Diese morphologische Differenzierung der Zellen, welche die Lage der Querwände bei der nächsten Teilung bestimmt, bewirkt die gesetzmäßige Aufeinanderfolge ungleich hoher Zellen in den Fäden einiger Chaetomorpha-Arten.

Besonders auffallend tritt die Gliederung des Fadens bei einer früher untersuchten Chatomorpha-Art in Erscheinung (KORNMANn 1968, Abb. 8 und 9), sie ist aber auch bei Chaetomorpha darwinii deutlich zu beobachten. Die in Abbildung 4 mit a gekennzeichnete Zelle wird am folgenden Tage in ungleich hohe Zellen geteilt. Die obere längere Zelle teilt sich nach 7 Tagen wieder unterhalb der Zellmitte (b), während die untere Schwesterzelle (c) sich etwa in der Mitte teilt. Auf diese Weise kommt es zu einer Gliederung des Fadens in vierzellige Gruppen, deren oberste Zelle am längsten, ihre Schwesterzelle am kürzesten ist, gefolgt von einem Paar nahezu gleichhoher Zellen. Diese Anordnung wiederholt sich am Ende des in Abbildung 4 dargestellten Fadens dreimal und kommt in der bildlichen Darstellung (Abb. $3 \mathrm{C}$ ) ebenfalls deutlich zum Ausdruck.

In Anbetracht der gegenteiligen Darstellung bei KöHLER (1956) muß ausdrücklich betont werden, daß die normal wachsende Chaetomorpha-Zelle keine basale Anreicherung des Protoplasten aufweist. KöHLERs Abbildung 1 liegt ein Faden zugrunde, „der längere Zeit in alter Kulturlösung gelegen hat" (p. 227) und dessen Wachstum durch tägliches Umsetzen angeregt wurde. In überständigen Chaetomorpha-Kulturen reichert sich der Zellinhalt basal an, auch das ist eine Polaritätserscheinung. Bei der Teilung solcher Zellen behält die basale Sihwesterzelle die Hauptmasse des gefärbten Inhalts. 
Diese Beobachtung KöHLERs ist zwar richtig, sie muß aber als Anomalität und nicht als Ausdruck einer morphologisch erkennbaren polaren Organisation der Chaetomorpha-Zelle angesehen werden.
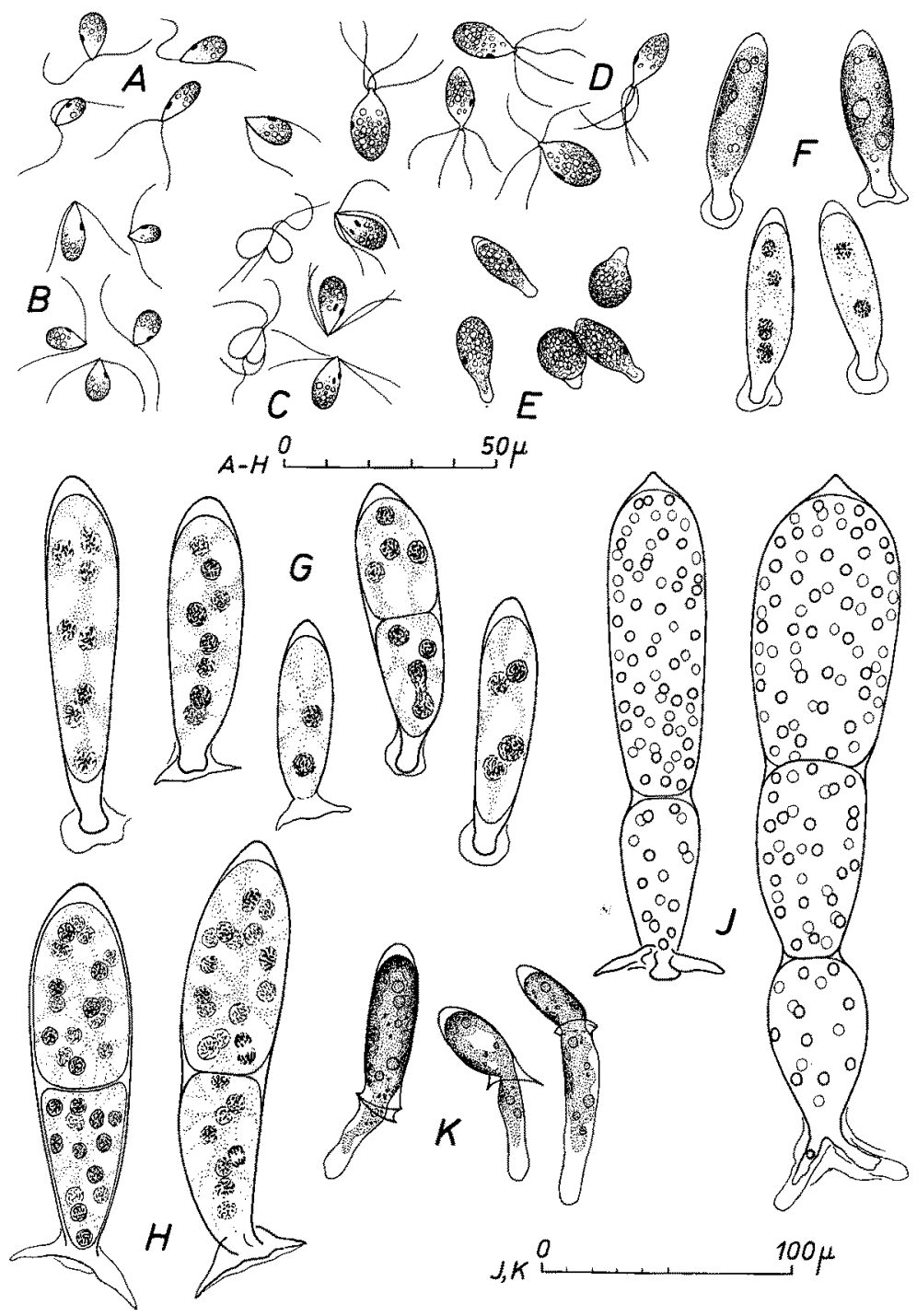

Abb. 12: Chaetomorpha darwinii. A-E Gameten, Zygoten, Zoosporen und ein Tag alte Keinlinge. $F-J$ Keimlinge im Alter von $8,12,16$ und 24 Tagen. $K$ Basal ausgewachsene Keimlinge, denen die ursprüngliche Haftscheibe als Kragen aufsitzt 


\section{LEBENSZYKLUS UND ENTWICKLUNG DER KEIMLINGE}

Etwa 20 der von den Wirtsalgen isolierten Pflanzen wurden in Einzelkulturen fertil. Es waren Sporophyten sowie Gametophyten verschiedenen Geschlechts. Daraus ist zu schließen, daß am natürlichen Standort beide Generationen gleichzeitig fertil werden.

Die in großer Menge verfügbaren Zoosporen und Gameten ermöglichten es, Reinkulturen aufzuziehen und Einzelheiten der Entwicklung zu studieren. Die Zoosporen sind meist 14 bis $15 \mu$ lang, ihre Breite schwankt zwischen 6 und $8 \mu$, so daß ihre äußere Form recht uneinheitlich erscheint (Abb. $12 \mathrm{D}$ ). Die vier etwas mehr als körperlangen Geißeln entspringen am Grunde einer ausgeprägten Papille. Die Größe der Gameten schwankt bei beiden Geschlechtern zwischen 7,5 und 12,5 $\mu$, die längeren sind im allgemeinen auch schlanker. Parthenogenetische Entwicklung wurde niemals beobachtet. Zygoten und Zoosporen entwickeln sich gleichartig.

Die ersten Stadien der Entwicklung sind in Abbildung 12 dargestellt. Die Keimlinge sitzen meist mehr oder weniger aufrecht auf ihrem ursprünglichen Geißelpol $(E)$. Flach auf dem Boden liegende Keimlinge lassen mitunter schon am ersten Tage eine hyaline apikale Kuppe erkennen, die später als deutlich aufgesetzte Spitze die Endzelle des Fadens krönt. Nach 8 Tagen haben die Keimlinge im allgemeinen die dreifache Länge ihres Anfangsstadiums erreicht, die Basis der Zelle steckt in einem scheibenartigen Haftorgan. Solche Keimlinge enthalten meist zwei, mitunter bereits vier Kerne $(F)$. Zwei, vier und acht Kerne findet man in 12 Tage alten Keimlingen, nur ganz wenige haben sich bereits geteilt $(G)$. Im Alter von 16 Tagen sind viele Keimlinge zweizellig, die obere Zelle weist mit großer Regelmäßigkeit 16 Kerne auf und ist in diesem Stadium nur wenig größer als die untere $(H)$.

24 Tage alte Keimlinge sind zwei- oder schon dreizellig $(J)$, ihre apikalen Zellen sind wesentlich größer als die basalen. In diesem Stadium läßt sich die Anzahl ihrer Kerne noch zählen, es sind jeweils $Z$ weierpotenzen. Jedoch erfolgen die synchronen Teilungen in den einzelnen Zellen eines Keimlings nicht im gleichen Rhythmus. Die Kerne der Basalzelle zeigen nur eine geringe Teilungsaktivität; ein Vergleich der Abbildungen $12 \mathrm{H}$ und $J$ läßt erkennen, daßs sie sich in dem Zeitraum von 8 Tagen nicht oder nur einmal geteilt haben, während die Kerne der Apikalzelle zwei Teilungsschritte vollzogen. Alle Beobachtungen deuten darauf hin, daß sich die Kerne in rasch wachsenden Pflanzen im Rhythmus von vier Tagen teilen. Auch in den großen Fadenzellen teilen sich die Kerne synchron.

Abbildung $13 A$ zeigt das Wachstum eines zu Beginn der Reihe 28 Tage alten dreizelligen Keimlings. Er wurde sekundär wieder zweizellig, indem der Protoplast der mittleren Zelle in die Basalzelle und das Rhizoid eindrang. Der gleiche Vorgang wiederholte sich zwischen dem 2. und 5. Januar. Auf diese Weise erneuert sich der Protoplast degenerierender Basalzellen, deren Kerne sich nicht mehr teilen und die nahezu farblos werden. Der eindringende Protoplast füllt im allgemeinen nur einen Teil des verzweigten Rhizoids aus, durchbricht seine Wandung an einer oder mehreren Stellen und wächst zu einem neuen kräftigen Haftorgan aus.

Der für die Beobachtung in Abbildung $13 \mathrm{~A}$ zufällig aus einer größeren Anzahl ausgewählte Keimling zeigte nicht die optimale Entwicklung. Seine Wachstums- 
geschwindigkeit verringerte sich merklich zwischen dem 27. Dezember und 2. Januar. Hier wirken sich Unregelmäßigkeiten im Rhythmus der Kernteilungen auf das Wachstum aus, wie sie schon im frühen Keimlingsstadium zu beobachten sind (Abb. $12 \mathrm{G}$ ).

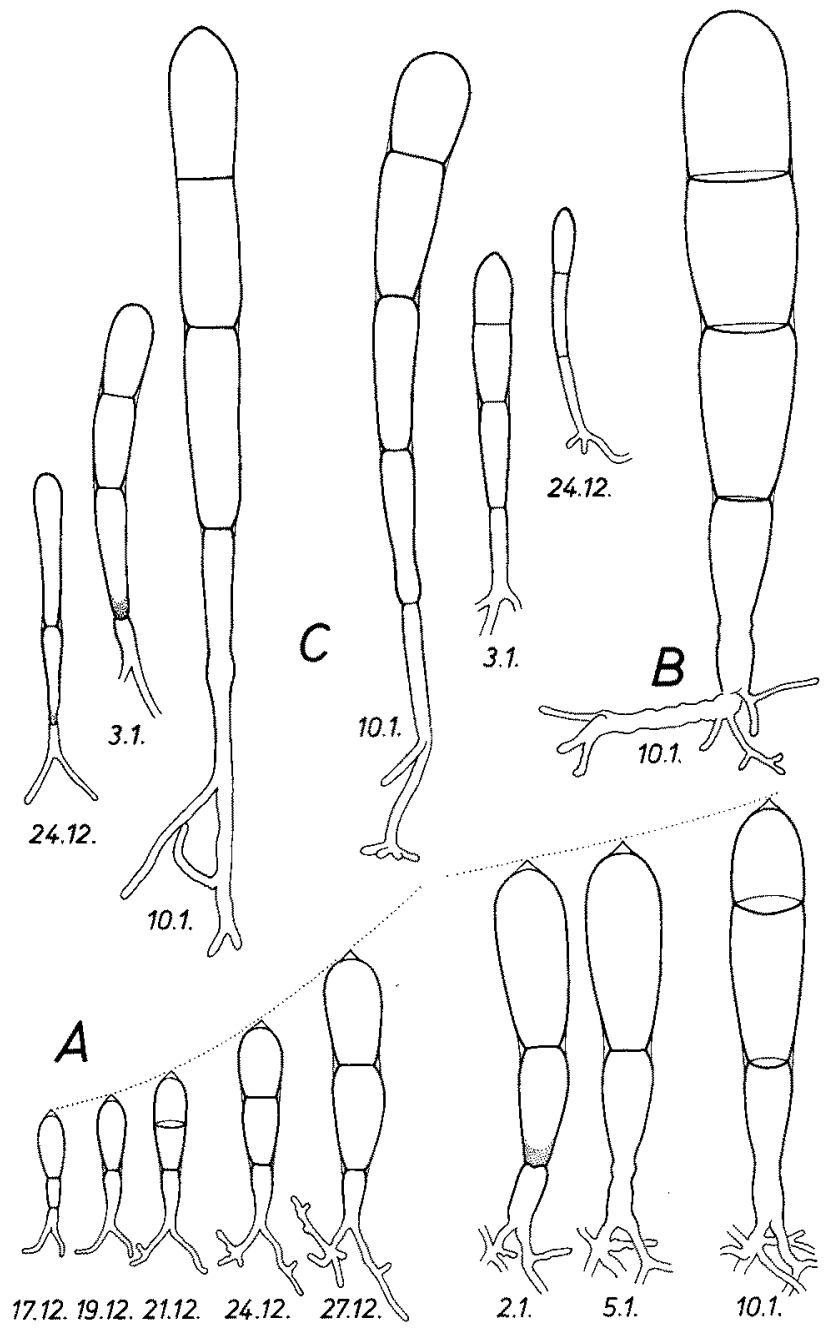

Abb. 13: Chaetomorpha darwinit. Unterschiedliche Entwicklung der Keimlinge in der gleichen Kulturschale $(A$ und $B)$ und in verschiedenen $(A, B$ gegenüber $C)$

Die größte in der gleichen Kulturschale gewachsene Pflanze ist zum Vergleich in Abbildung $13 B$ dargestellt. Solche Unterschiede gleichen sich im Laufe der Entwicklung nicht aus, sondern treten immer stärker in Erscheinung. Einzelne Pflanzen wurden über $60 \mathrm{~cm}$ lang, andere blieben bei gleichen Kulturbedingungen unter $10 \mathrm{~cm}$. Ein Teil der Keimlinge kam nicht über das zweizellige Stadium hinaus. Auch das Substrat vermag 
Form und Entwicklung der Keimlinge entscheidend zu beeinträchtigen; die Zusammenhänge sind ungeklärt. Unter sonst völlig gleichen Bedingungen können die in verschiedenen Kulturschalen sich entwickelnden Keimlinge von Chaetomorpha darwinii und anderen Arten der Gattung ganz unterschiedlich aussehen. Entweder wird eine Haftscheibe gebildet, die später durch Rhizoide ersetzt wird (Abb. $12 F-J$ ). Aus solchen Keimlingen entwickeln sich gedrungene, dicke Fädchen, wie sie in Abbildung $13 A$ und $B$ dargestellt sind. In anderen Schalen kommt es dagegen nicht zur Ausbildung einer Haftscheibe, es entstehen lange dünnfädige Keimlinge, wie man sie auch an der Oberfläche der Kulturflüssigkeit antrifft. Im allgemeinen entwickeln sich diese Keimlinge, wenn es überhaupt zu einer Teilung kommt, langsamer als die auf einer Haftscheibe verankerten; die aus ihnen entstehenden Keimlinge sind schlanker (Abb. $13 \mathrm{C}$ ). Schließlich kann es vorkommen, daß die Keimlinge zuerst eine Haftscheibe bilden, die Basis der Zelle sich dann aber schlauchartig verlängert, so daß die ursprüngliche Haftscheibe dem fädigen Keimling als Kragen aufsitzt (Abb. $12 \mathrm{~K}$ ).

Zur Aufzucht im Laboratorium wird man immer die schönsten und raschwüchsigsten Keimlinge auswählen. Größe und Gestalt der Zellen kann bei verschiedenen Fäden, aber selbst auch längs desselben Fadens stark variieren, was für die Begrenzung der Art nach morphologischen Merkmalen zu berücksichtigen ist (Abb. $3 E$ ). In gut gepflegten Kulturen können die Fäden über ein Jahr alt werden. Aus dem vegetativen basalen Abschnitt erneuert sich immer wieder der prächtige Faden mit seinen Riesenzellen, die dann - im allgemeinen im Anschluß an einen Wechsel der Nährlösung fertil werden.

\section{ZUSAMMENFASSUNG}

1. Chaetomorpha darwinii aus der Flora Südaustraliens, die stattlichste Art der Gattung, hat isomorphen Generationswechsel. Parthenogenetische Entwicklung der Gameten wurde nicht beobachtet.

2. Der Rhythmus der synchronen Kernteilungen, der sich in den Zellen der Keimlinge nachweisen läßt, regelt wahrscheinlich alle Wachstumsvorgänge.

3. Die Zelle von Chatomorpha darwinit wächst in einer äquatorialen Zone gleichzeitig in die Länge und Breite. Sie wird tonnenförmig, weil die Querwände nicht wachstumsfähig sind. Wachstum und Morphologie der Zelle sowie die Drehung des wachsenden Fadens um seine Längsachse gehen auf die Verlängerung zweier gekreuzter Mikrofibrillensysteme zurück.

4. Die tägliche Zuwachsrate ist bei allen Zellen gleich. Das Wachstum erfolgt während der täglichen Lichtperiode schneller als in der Dunkelheit.

5. Die Zuwachskurve eines Fadens ergibt das Schaubild einer Exponentialfunktion. Sie erklärt sich als Summe der gleichmäßigen Streckung aller Einzelzellen, die sich in einem bestimmten Rhythmus teilen.

6. Bei der zentripetalen Teilung der Zelle rückt die Querwand radial mit gleichmäßiger Geschwindigkeit vor; dabei verringert sich die in der Zeiteinheit gebildete Membranfläche immer mehr.

7. Die normal wachsende Chaetomorpha-Zelle zeigt keine morphologische Polarität. Polaritätsäußerungen sind (a) die während der Schwärmerreifung auftretende 
Spontanplasmolyse, wobei der Wandbelag an der oberen Querwand haftet, (b) das Auswachsen der Endzelle eines Fadenstïckes an seiner morphologischen Basis, (c) die Gliederung des Fadens in Abschnitte von jeweils vier Zellen unterschiedlicher Höhe.

Danksagungen. Frau S. C. DUCKer und der Direktion des Botanischen Instituts Melbourne gebührt mein verbindlicher Dank für die Übersendung der Algenproben, auf denen sich das Untersuchungsobjekt in Kultur entwickelte. Meinem technischen Assistenten, Herrn P.-H. SAHLING, danke ich für die vielfältige Hilfe bei der Durchführung der Arbeit.

\section{ZITIERTE LITERATUR}

Frei, E. \& Preston, R. D., 1961a. Cell wall organization and wall growth in the filamentous green algae Cladopbora and Chatomorpha. I. The basic structure and its formation. Proc. R. Soc. (B) 154, 70-94.

- - 1961b. Cell wall organization and wall growth in the filamentous green algae Cladophora and Chaetomorpha. II. Spiral structure and spiral growth. Proc. R. Soc. (B) 155, 55-77.

GreEN, P. B., 1954. The spiral growth pattern of the cell wall in Nitella axillaris. Am. J. Bot. 41, 403-409.

Kesseler, H., 1960. Morphologische und zellphysiologische Untersudiungen an Chaetomorpha linum. Helgoländer wiss. Meeresunters. 7, 114-124.

KöHLER, K., 1956. Entwicklungsgeschichte, Geschlechtsbestimmung und Befruchtung bei Chaetomorpha. Arch. Protistenk. 101, 223-268.

Kornmann, P., 1968. Das Wachstum einer Chaetomorpha-Art von List/Sylt. Helgoländer wiss. Meeresunters. 18, 194-207.

Nicolat, E. \& Preston, R. D., 1959. Cell-wall studies in the Chlorophyceae. Differences in structure and development in the Cladophoraceae. Proc. R. Soc. (B) 151, 244-255.

Price, J. R. \& Ducker, S. C., 1966. The life history of the brown alga Splachnidium rugosum. Phycologia 5, 261-273.

Schumacher, W., 1967. Physiologie. 4. Der Einfluß der Außenwelt. F. Der Entwicklungsgang und seine Abhängigkeit von äußeren und inneren Faktoren. In: Lehrbuch der Botanik für Hodhschulen. Begr. von E. Strasburger u. a. 29. Aufl. G. Fischer, Stuttgart, 332-337.

Stosch, H. A. von \& Drebes, G., 1964. Entwicklungsgeschichtliche Untersuchungen an zentrischen Diatomeen. 4. Die Planktondiatomee Stephanopyxis turris - ihre Behandlung und Entwicklungsgeschichte. Helgoländer wiss. Meeresunters. 11, 209-257.

Anschrift des Autors: Dr. P. Kornmann

Biologische Anstalt Helgoland

Meeresstation

2192 Helgoland 